\title{
Membraneous Glomerulonephritis and Non-Hodgkin's Lymphoma in a Patient with Primary Sjögren's Syndrome
}

\author{
Nozomi Iwanaga ${ }^{1}$, Makoto Kamachi ${ }^{1}$, Keita Fujikawa ${ }^{1}$, Toshiyuki Aramaki ${ }^{1}$, \\ Yasumori Izumi ${ }^{1}$, Kazuhiko Arima ${ }^{1}$, Mami Tamai ${ }^{1}$, Kouichiro Aratake ${ }^{1}$, \\ Hideki Nakamura ${ }^{1}$, Tomoki Origuchi ${ }^{2}$, Hiroaki Ida ${ }^{1}$, Atsushi Kawakami ${ }^{1}$, \\ Takashi Taguchi ${ }^{3}$ and Katsumi Eguchi ${ }^{1}$
}

\begin{abstract}
The most common renal manifestation of Sjögren's syndrome is tubulointerstitial nephritis, and glomerular disease is rare (3). A 62-year-old woman with primary Sjögren's syndrome developed nephrotic syndrome. Kidney biopsy was consistent with membraneous glomerulonephritis. Steroid pulse therapy was not effective. Three months later she was diagnosed with non-Hodgkin's lymphoma of the tongue, and she was given CHOP therapy and radiation. Both the lymphoma and membraneous glomerulonephritis were resolved.
\end{abstract}

Key words: Sjögren's syndrome, membraneous glomerulonephritis, lymphoma

(DOI: 10.2169/internalmedicine.46.1835)

\section{Introduction}

Sjögren's syndrome is an autoimmune disease characterized by lymphocytic infiltration of salivary and lacrimal glands, leading to the progressive destruction of these glands, and by the production of autoantibodies (1). Extraglandular manifestations are frequent and may include renal involvement (2). Tubulointerstitial nephritis with defects in tubular function is the most common renal manifestation of Sjögren's syndrome, and glomerular disease is rare (3). Malignant lymphoma was first reported in patients with Sjögren's syndrome in 1951 (4). Subsequently, adequate studies established strong associations between malignant non-Hodgkin's lymphoma (NHL) and Sjögren's syndrome. The risk of NHL in patients with Sjögren's syndrome is estimated as being 44 times greater than that in the normal population (5). Here, we report a patient with primary Sjögren's syndrome who developed membraneous glomeluronephritis and non-Hodgkin's lymphoma of the tongue. The patient's renal insufficiency and lymphoma resolved after treatment with CHOP and radiation.

For editorial comment, see p 155.

DOI: $10.2169 /$ internal medicine.46.0177

\section{Case Report}

The patient was a 62-year-old woman who was diagnosed with primary Sjögren's syndrome 10 years previously. Since 1993, urinary beta2-microglobulin had been continuously high, but proteinuria had been negative. She had not been given steroid or immunosuppressive treatment. On May 20, 2000, she developed proteinuria, and on June 15, 2000, she was admitted to our hospital for examination.

On admission, her blood pressure was 90/52 $\mathrm{mmHg}$, pulse $66 \mathrm{bpm}$, and body temperature $36.5^{\circ} \mathrm{C}$. She had pretibial edema. There was purpura and pigmentation on her lower extremities.

Urinalysis showed $4.4 \mathrm{~g}$ /day proteinuria, 5-10 red blood

\footnotetext{
${ }^{1}$ First Department of Internal Medicine, Graduate School of Biomedical Sciences, Nagasaki, University, Nagasaki, ${ }^{2}$ Nagasaki University of Health Sciences, Nagasaki and ${ }^{3}$ Second Department of Pathology, Nagasaki University School of Medicine, Nagasaki

Received for publication 23, 2006; Accepted for publication 16, 2006

Correspondence to Dr. Nozomi Iwanaga, nozomi0620@yahoo.co.jp
} 


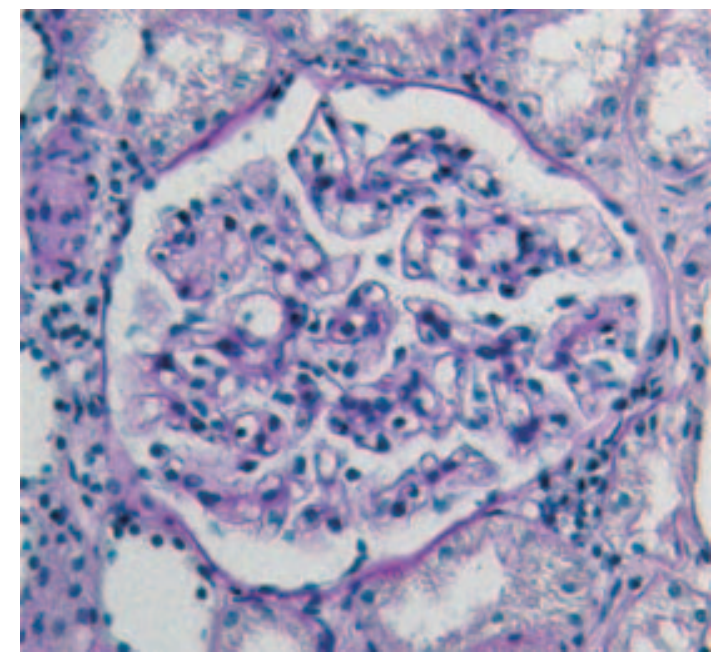

Figure 1. Light microscopy. Glomeruli show focal thickening of the basement membrane and mild mesangial proliferation (PAS, 400x).

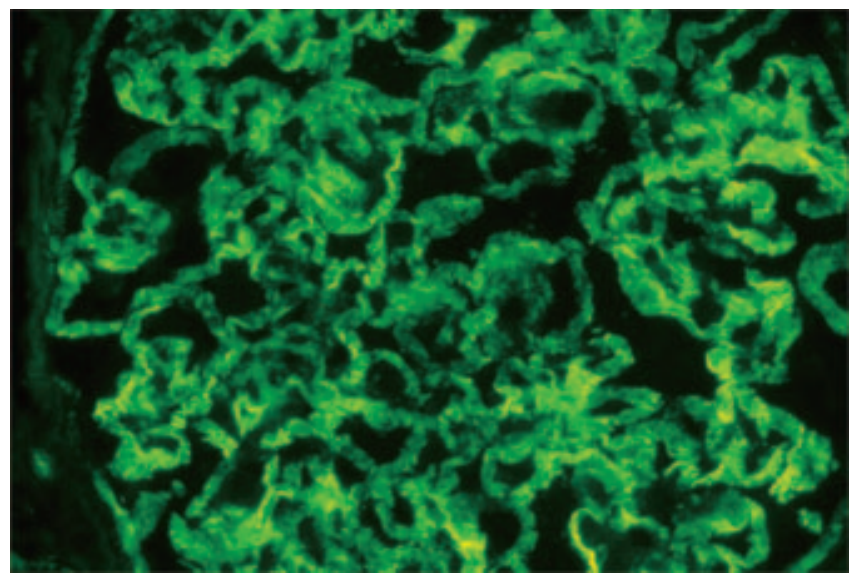

Figure 2. The immunofluorescent examination reveals granular deposits of IgG, C3, and C1q strongly in the capillary wall and focally in the mesangium (This figure shows deposits of IgG).

cells per high-power field, and fatty casts. Total serum protein was $4.8 \mathrm{~g} / \mathrm{dl}$, serum albumin was $2.5 \mathrm{~g} / \mathrm{dl}$, and total cholesterol was $255 \mathrm{mg} / \mathrm{dl}$. These findings met the criteria of nephrotic syndrome. Blood urea nitrogen was $18 \mathrm{mg} / \mathrm{dl}$, creatinine was $1.0 \mathrm{mg} / \mathrm{dl}$, and creatinine clearance was 54 $\mathrm{ml} / \mathrm{min}$. Other hematometry and chemistry were within normal limits. Serological tests were positive for anti-nuclear antibodies (ANA) 640× with a speckled pattern, positive for both anti-SS-A and anti-SS-B antibodies and negative for antibodies against DNA, ribonucleoproteins (RNP), Sm, and antineutrophil cytoplasmic antibodies. The levels of C3, C4, and total hemolytic complement $\left(\mathrm{CH}_{50}\right)$ were within normal limits. The soluble IL-2 receptor was $900 \mathrm{U} / \mathrm{ml}$. There was no evidence of hepatitis $\mathrm{C}$ virus, human T-cell lymphotropic virus type I, or Epstein-Barr virus infection. Cryoglobulin was not detected.

Percutaneous renal biopsy was performed on June 22. The

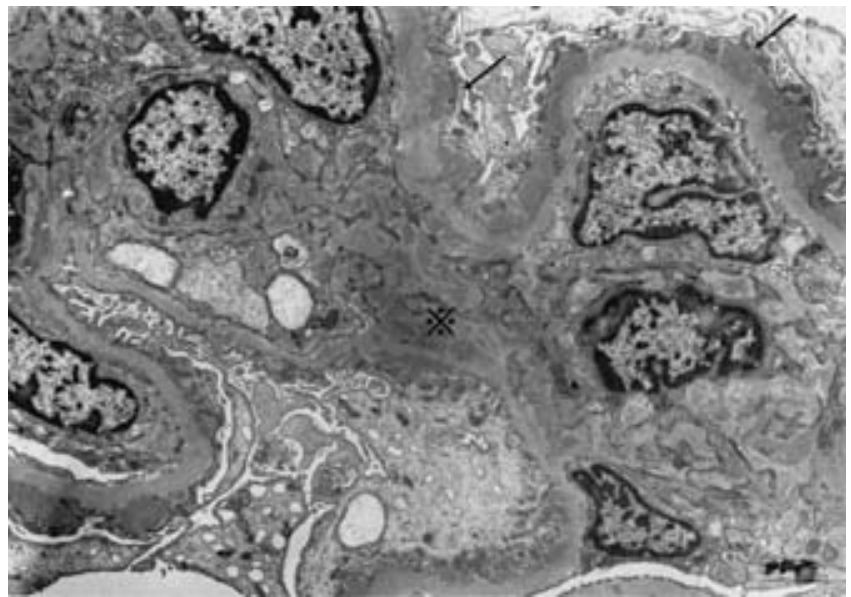

Figure 3. Electron-microscopy. Subepithelial electrondense deposits are seen along the basement membrane (arrows) and mesangial electron-dense deposits were also detected $(*)$.

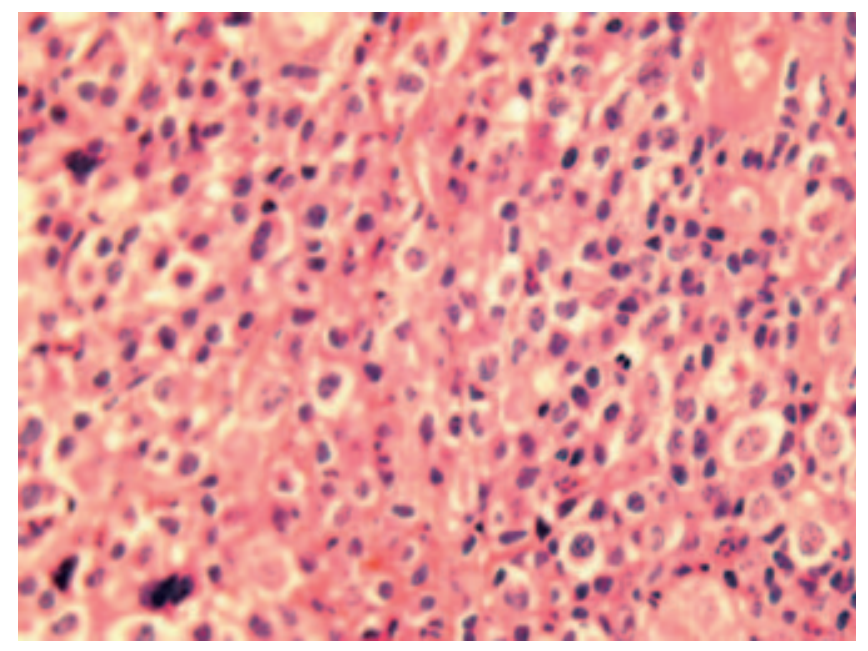

Figure 4. Lingual biopsy specimen. The tumor cells are composed primarily of medium-sized to large centroblastlike cells. They have pale, oval nuclei with a few nucleoli (HE, 400x).

specimen included 11 glomeruli, and 9 of these were sclerosed. Two glomeruli showed focal thickening of the basement membrane and mild mesangial proliferation (PAS staining, Fig. 1). No malignant cells were observed in the specimen. Immunofluorescent examination revealed granular deposits of IgG, C3, and C1q strongly in the capillary wall and focally in the mesangium (Fig. 2). On electron microscopy, subepithelial and mesangial electron-dense deposits were noted (Fig. 3). From the above pathological findings, the case was diagnosed as membraneous glomerulonephritis of the secondary type.

Corticosteroid pulse therapy, methylprednisolone $250 \mathrm{mg} /$ body for 3 days, was performed and repeated twice. Thereafter, oral prednisolone, $40 \mathrm{mg} /$ day, was started, but 2-3 g/ day proteinuria was continued. In August, we found an ulcer at the base of the patient's tongue. Lingual biopsy was performed on August 28. Below the ulcerated surface, diffuse 


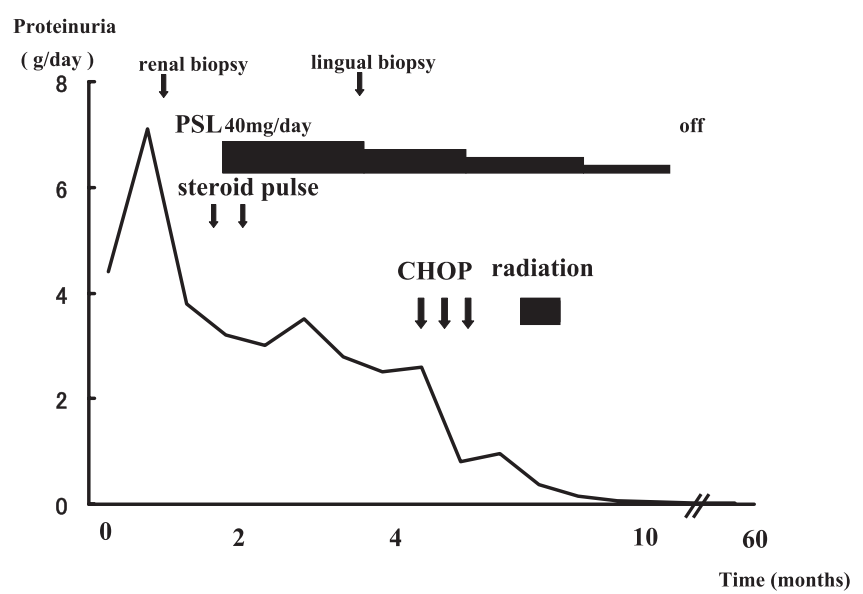

Figure 5. Clinical course. Corticosteroid pulse therapy was performed twice, and oral prednisolone, $40 \mathrm{mg} / \mathrm{day}$, was started. But urinary protein did not decrease sufficiently. After the diagnosis of malignant lymphoma, chemotherapy with the CHOP regimen and radiation therapy was administered. The lymphoma cells then disappeared, and urinary protein decreased to $0.3 \mathrm{~g} / \mathrm{day}$. There have been no signs of relapse over a period of 60 months.

atypical lymphoid infiltration was found using hematoxylin and eosin (HE) stain. The tumor cells were composed primarily of medium-sized to large centroblast-like cells (Fig. 4). Mucosa-associated lymphoid tissue (MALT) lymphoma frequently complicates Sjögren's syndrome. Histological characteristics of MALT lymphoma have been identified to include the presence of a diffuse infiltrate of centrocyte-like cells intermingled with immunoblasts of the same clone, plasma cell differentiation of the tumor cells, and reactive intratumoral lymphoid follicle. However, these features were not seen in the present case. Immunohistochemical results showed that the neoplastic cells expressed the B-cell antigen CD20. The diagnosis was diffuse large Bcell lymphoma. Staging determined that the lymphoma was localized to the tongue. Chemotherapy with the CHOP regimen (cyclophosphamide $750 \mathrm{mg} / \mathrm{m}^{2}$ div, doxorubicin $50 \mathrm{mg}$ / $\mathrm{m}^{2}$ div, vincristine $1.4 \mathrm{mg} / \mathrm{m}^{2}$ iv, prednisolone $100 \mathrm{mg}$ po) was started in October. It was subsequently repeated for a total of 3 times, and thereafter predonisolone therapy, 25 $\mathrm{mg}$, was continued for 4 weeks and was reduced by $2.5 \mathrm{mg}$ every 4 weeks. In addition, radiation therapy was given in December. After this therapy, the lingual ulcer disappeared, and urinary protein decreased from $2.1 \mathrm{~g} /$ day to $0.3 \mathrm{~g} /$ day. As of July 2005, she was no longer being given prednisolone but had no relapse of either non-Hodgkin's lymphoma or membraneous glomerulonephritis. (Fig. 5)

\section{Discussion}

Lymphomas that appear after a prolonged course of Sjögren's syndrome are usually localized extranodal lowgrade B cell non-Hodgkin's lymphoma (6) and are a good target for CHOP therapy. Nephrotic syndrome resulting from membraneous glomerulonephritis is clinically wellrecognized and generally shows a good response to steroid or immunosuppressive therapy. In contrast, nephrotic syndrome resulting from paraneoplastic glomerulonephritis is resistant to immunosuppressive therapies but in some cases responds to CHOP therapy for malignant lymphoma. We have reported a rare case of primary Sjögren's syndrome complicated with membraneous glomerulonephritis and nonHodgkin's lymphoma. In the present case, the renal biopsy showed subepithelial and mesangial deposits on electron microscopy, and subepithelial and mesangial deposits of IgG, $\mathrm{C} 3$, and $\mathrm{C} 1 \mathrm{q}$ on immunofluorescent examination. These findings are often seen in secondary forms of membraneous glomerulonephritis patients with Sjögren's syndrome or malignancy-associated membraneous glomerulonephritis (3, 7). Although we could not exclude the possibility of secondary membraneous glomerulonephritis due to Sjögren's syndrome, this case was more likely paraneoplastic glomerulonephritis related to malignant lymphoma for the following reasons: 1) Clinical prevalence and course; interstitial nephritis is the major renal complication of primary Sjögren's syndrome, but membranous glomerulonephritis is rare. In contrast, membraneous glomerulonephritis resulting from malignancies is a well-known clinical manifestation with an incidence of between $3 \%$ and $13 \%$. Associated malignancies occur primarily in the lung and gastrointestinal tract (8). Glomerulonephritis with malignant lymphoma is not as frequent, but there have been at least 37 reports of glomerulonephritis associated with non-Hodgkin's lymphoma (9-19). indicating a great variety of glomerular lesions, including membraneous glomerulonephritis (33\%) (9). In addition, $40-45 \%$ of patients with membraneous glomerulonephritis related to malignancy develop nephrotic syndrome prior to the diagnosis of their tumor, suggesting their etiological relationship (20). In the present case, membranous glomerulonephritis and nephrotic syndrome were detected 3 months before the diagnosis of malignant lymphoma. 2) Serology: no anti-ds-DNA antibody, antineutrophil cytoplasmic antibodies or hypocomplementemia were detected. 3) Response to chemotherapy: nephrotic syndrome resulting from paraneoplastic syndrome has been reported to be steroid-resistant and to responsive to CHOP therapy. For example, a retrospective study (21) with non-Hodgkin's lymphoma and chronic lymphocytic leukemia (CLL) in 700 patients showed 5 cases of membraneous glomerulonephritis-associated lymphoma and CLL. Three of those cases achieved complete remission after chemotherapy (CHOP therapy) (21). Banks reported that aggressive therapy of the lymphoma alone results in complete remission of membraneous glomerulonephritis. In some cases of membraneous glomerulonephritis, the condition takes several months to resolve; therefore, the steroid therapy prior to CHOP therapy in the present case may have facilitated the clinical remission of nephritic syndrome. However, proteinuria, which did not respond well to high-dose steroid therapy for 4 months, rapidly disappeared with a reduction of lymphoma in response to CHOP 
therapy. Remission of both lymphoma and membraneous glomerulonephritis has been maintained for 5 years.

The pathogenesis of paraneoplastic glomerulonephritis is not fully understood, but has been assumed to be mediated by subepithelial immune complexes composed of tumor antigen and antibody, and other nonlymphocyte antigens including viral antigens (22). Sutherland and Mardiney have identified immune complex deposits containing virus-related antigen in the glomeruli of patients suffering from leukemia or lymphoma (23). It is likely that antibodies to lymphocyte or viral antigen are produced in the course of progression to lymphoma, leading to the formation of immune complex, which then plays an important role in the onset of paraneoplastic glomerulonephritis. In the present case, there was immune complex deposition along the glomerular basement membrane, suggesting the pathogenesis of immune com- plexes composed of unidentified antibodies and antigens. The sinusoidal tract is the most commonly involved site of malignant lymphoma complicated with Sjögren's syndrome, while the base of the tongue is affected in only $8 \%$ of cases (24). In the present case, the tongue ulcer was the primary origin of the malignant lymphoma, indicating the rare clinical manifestation of lymphoma complicated with Sjögren's syndrome.

In conclusion, we encountered a rare case of a patient with Sjögren's syndrome complicated with membraneous glomerulonephritis resulting from paraneoplastic syndrome related to malignant lymphoma. We recommend that patients with Sjögren's syndrome be carefully evaluated for occult malignancy, in particular malignant lymphoma, when they develop membraneous glomerulonephritis.

\section{References}

1. Fox RI, Howell FV, Bone RC, Michelson P. Primary Sjögren syndrome: Clinical and immunopathologic features. Semin Arthritis Rheum 14: 77-105, 1984.

2. Bossini N, Savoldi S, Franceschini F, et al. Clinical and morphological features of kidney involvement in primary Sjögren's syndrome. Nephrol Dial Transplant 16: 2328-2336, 2001.

3. Shioji R, Furuyama T, Onodera S, Saito H, Ito H, Sasaki Y. Sjögren's syndrome and renal tubular acidosis. Am J Med 48: 456-463, 1970.

4. Rothman S, Block M, Hauser FV. Sjögren's syndrome associated with lymphoblastoma and hypersplenism. AMA Arch Derm Syphilol 63: 642-643, 1951.

5. Kassan SS, Thomas TL, Moutsopoulos HM, et al. Increased risk of lymphoma in sicca syndrome. Ann Intern Med 89: 888-892, 1978.

6. Anaya JM, McGuff HS, Banks PM, Talal N. Clinicopathological factors relating malignant lymphoma with Sjögren's syndrome. Semin Arthritis Rheum 25: 337-346, 1996.

7. Jefferson JA, Couser WG. Therapy of membraneous nephropathy associated with malignancy and secondary causes. Semin Nephrol 23: 400-405, 2003.

8. Keur I, Krediet RT, Arisz L. Glomerulopathy as a paraneoplastic phenomenon. Neth J Med 34: 270-284, 1989.

9. Strippoli GF, Manno C, Rossini M, Occhiogrosso G, Maiorano E, Schena FP. Primary cerebral lymphoma and membranous nephropathy: a still unreported association. Am J Kidney Dis 39: E22, 2002.

10. Matsui M, Matsuzaki M, Shimamoto $Y$, et al. Malignant lymphoma with acute renal failure and nephrotic syndrome. Rinsho Ketsueki 31: 229-233, 1990 (in Japanese).

11. Flury W, Wegmuller E, Zeltner $T$, Niesel P. Malignant nonHodgkin's lymphoma with visual disorders and nephrotic syndrome. Schweiz Med Wochenschr 112: 448-453, 1982 (In German).

12. Belghiti D, Vernant JP, Hirbec G, Gubler MC, Andre C, Sobel A. Nephrotic syndrome associated with T-cell lymphoma. Cancer 47: 1878-1882, 1981.

13. Pollock CA, Ibels LS, Levi JA, Eckstein RP, Wakeford P. Acute renal failure due to focal necrotizing glomerulonephritis in a patient with non-Hodgkin's lymphoma. Resolution with treatment of lymphoma. Nephron 48: 197-200, 1988.

14. Messiaen T, Cosyns JP, Ferrant A, Jadoul M. Splenic lymphoma presenting as necrotizing glomerulonephritis. Clin Nephrol 50: 387-389, 1998.

15. Zahner J, Bach D, Malms J, Schneider W, Diercks K, Grabensee B. Glomerulonephritis and malignant lymphoma. Mostly men with low-grade lymphoma with various forms of glomerulonephritis. Med Klin (Munich) 92: 712-719, 1997 (In German).

16. Zahner J, Gerharz CD, Bach D, et al. Association of primary renal non-Hodgkin's lymphoma with mesangioproliferative glomerulonephritis. Am J Hematol 53: 126-132, 1996.

17. Weinstein T, Chagnac A, Gafter U, et al. Unusual case of crescentic glomerulonephritis associated with malignant lymphoma. A case report and review of the literature. Am J Nephrol 10: 329$332,1990$.

18. Giron Gonzalez JA, Yebra Bango M, Marino Morales F, Menendez Caro JL, Diego Marin FJ, Durantez Martinez A. The association of non-Hodgkin's lymphoma with glomerulonephritis. Postgrad Med J 62: 1141-1145, 1986.

19. Khan MA, Akhtar M, Taher SM. Membranoproliferative glomerulonephritis in a patient with Primary Sjögren's syndrome. Report of a case with review of the literature. Am J Nephrol 8: 235-239, 1988.

20. Lee JC, Yamauchi H, Hopper Jw Jr. The association of cancer and nephrotic syndrome. Ann Intern Med 64: 41-51, 1966.

21. Da' as N, Polliack A, Cohen Y, et al. Kidney involvement and renal manifestations in non-Hodgkin's lymphoma and lymphocytic leukemia: a retrospective study in 700 patients. Eur J Haematol 67: 158-164, 2001.

22. Moulin B, Ronco PM, Mougenot B, Francois A, Fillastre JP, Mignon F. Glomerulonephritis in chronic lymphocytic leukemia and related B-cell lymphomas. Kidney Int 42: 127-135, 1992.

23. Sutherland JC, Mardiney MR Jr. Immune complex disease in the kidneys of lymphoma-leukemia patients: The presence of an oncornavirus-related antigen. J Natl Cancer Inst 50: 633-644, 1973.

24. Hanna E, Wanamaker J, Adelstein D, Tubbs R, Lavertu P. Extranodal lymphomas of the head and neck. A 20-year experience. Arch Otolaryngol Head Neck Surg 123: 1318-1323, 1997.

(C) 2007 The Japanese Society of Internal Medicine http://www.naika.or.jp/imindex.html 